food or drink for three hours before receiving the drug, but we may have been unduly cautious. Provided that the drug is not administered in such a manner that unconsciousness supervenes, the risk of vomiting should be no greater than in any conscious subject. There is another reason why patients should remain awake throughout. There was a high incidence of respiratory obstruction in those who went to sleep which was usually not detected clinically. It is possible that the transient apnoea after intravenous diazepam reported by Hellewell (1968) may have been due to undetectable respiratory obstruction

If sedation is required for conservative dentistry then the work reported here suggests that intravenous diazepam administered in the manner described, followed by local analgesia, is physiologically more acceptable than other techniques hitherto investigated.

We extend our sincere gratitude to the patients who volunteered to take part in this study and made it possible. Our thanks are due to Professor Shovelton for making facilities available to us at the Dental School and to Mr. N. Hall, who undertook the dental surgery. The work was supported in part by the Endowment Fund of the United Birmingham Hospitals. Some of the costs of investigations were defrayed by Roche Products Limited.

Buchwald, K. W., and Cori, C. F. (1931). Fournal of Biological Chemistry, 92, 355.

Central Health Services Council (1967), Report on Dental Anaesthesia, p. 8. London, H.M.S.O.

Dalen, J. E., et al. (1969) Anesthesiology, 30, 259.

Healy, T. E. J., Edmondson, H. D., and Hall, N. (1970). British Dental fournal, 128, 22.

Healy, T. E. J., Lautch, H., Hall, N., Tomlin, P. J. and Vickers, M. D. (1970). British Medical fournal, 3, 13.

Hellewell, J. (1968). In Diazepam in Anaesthesia, ed. P. F. Knight and C. G. Burgess, p. 52. Bristol, Wright

MacDonald, A. G., and Carmichael, A. F. (1970) Anaesthesia, 25, 127.

Poswillo, D. (1967). New Zealand Dental fournal, 63, 265.

Tomlin, P. J., Howarth, F. H., and Robinson, J. S. (1968). Lancet, 1,

Wise, C. C., Robinson, J. S., Heath, M. J., and Tomlin, P. J. (1969). British Medical fournal, 2, 540 .

\title{
Interdisciplinary Study of Diazepam Sedation for Outpatient Dentistry
}

\author{
T. E. J. HEALY, ${ }^{*}$ M.B., F.F.A. R.C.S., D.A. ; HENRY LAUTCH, † L.R.C.P., L.R.C.S., D.P.M. ; N. HALL, $\ddagger$ B.D.S. \\ P. J. TOMLIN, $\$ M.B., B.S., F.F.A. R.C.S. ; M. D. VICKERS, $\|$ M.B., F.F.A. R.C.S., D.A.
}

\begin{abstract}
Cummary: Patients unable to submit themselves to routine dental treatment under local anaesthesia were studied during treatment under diazepam sedation accompanied by local anaesthesia, and compared with a matched control group for psychiatric assessment. Physiological responses, operating conditions, amnesia, pain threshold, and recovery were all assessed by various tests.

Some of the patients had an anxiety neurosis, and several had been referred because of previous failure to complete dental treatment. Satisfactory conditions were obtained in all but two instances, and no adverse physiological responses occurred with diazepam in an intravenous dose of $0.2 \mathrm{mg}$. $/ \mathrm{kg}$. Patients were clinically safe to leave accompanied by a responsible adult within one hour of administration of the drug. Some patients showed an improvement in attitude towards dentistry following treatment.
\end{abstract}

\section{Introduction}

It is generally agreed that there are some people who are unable to submit to dental procedures under local anaesthesia, but their number is unknown (Central Health Services Council, 1967). A variety of regimens involving various drugs have been recommended to meet the special problems of such patients. No single specialty, however, is equipped to consider all aspects of such a complex problem involving, as it must, a consideration of such factors as the history and personality of the patients, and the short-term and long-term physiological and psychological effects of drug-assisted treatment on them.

In an attempt to answer some of these questions the departments of conservative dentistry, psychiatry, and anaesthetics in the University of Birmingham have carried out a study of the technique of sedation with intravenous diazepam, together with local anaesthesia, for the management of outpatients unable to tolerate oral surgery or dental conservation under local anaesthesia alone. The patients were studied at various times throughout their attendances at the Birmingham Dental Hospital by different members of the team; for the sake of clarity, however, the methods and results are presented in this paper as seen by the discipline most likely to be interested in that part of the investigation, and the whole study is reviewed in the discussion.

\section{Dental Aspect}

\section{Selection of Patients}

All patients were interviewed by the dental surgeon and assessed regarding their suitability for inclusion in the investigation. The assessment was based on their response to past dental treatment, their attitude to dentistry, and the reasons for their fears. Those with cardiovascular and respiratory diseases were excluded.

If a patient was considered suitable for inclusion in the trial the method of treatment was explained and he was encouraged to ask questions. No attempt was made to persuade or influence patients to accept treatment, which was normally arranged to be undertaken a week later.

\section{Methods}

All patients were prepared as for an outpatient dental general anaesthetic, instructed to have nothing to eat and drink 
for three hours before treatment, and to arrange to be accompanied home after treatment No premedication was given. Patients were placed in the supine position in the dental chair and diazepam was administered intravenously, undiluted, to a total dose of $0.2 \mathrm{mg}$. $/ \mathrm{kg}$. (see below). Immediately after the administration of diazepam a suitable local anaesthetic block was placed, $2 \%$ lignocaine with adrenaline $1: 80,000$ being used. The dental procedures were started as soon as possible. A high-speed aspirator was used in all cases, with mouth packs to seal the oral cavity from the pharynx.

Operative conditions were classified into four grades. Goodif the condition compared favourably with that expected during outpatient dentistry with local anaesthesia in normal subjects; fair-if satisfactory working conditions resulted but the patient made slight head or limb movements; poor-if movement or phonation resulted in a disturbance of concentration on the technical side of the operative procedures; and bad-if operative procedures had to be abandoned or limited because of uncontrollable movements or distress.

The pain threshold was measured by passing a steadily increasing electric current through a tooth until the patient indicated pain by raising his hand. Control readings were made before the administration of diazepam, and readings were repeated at intervals during treatment, the same tooth being used.

\section{Results}

Fifty-four courses of treatment were undertaken for 44 patients ( 25 females, 19 males). Their ages ranged from 15 to 54 years. Twenty-seven courses of treatment involved conservation only, four comprised both conservation and oral sur gical procedures, while the remaining 23 cases involved surgical treatment only. The duration of treatment ranged from 5 to 115 minutes.

The operative conditions were classified as good in 41 cases, fair in 11, poor in 2, and bad in none.

The pain threshold to electrical stimulation remained unchanged throughout the course of treatment. After being given diazepam, however, the patients' attitude to the stimulus became one of complete unconcern, and the magnitude of their motor reactions diminished. In all but two of the courses of treatment diazepam produced good sedation and rendered the patients co-operative, drowsy, relaxed, and tranquil. The persistence of conscious co-operation and verbal access represented an advantage of the technique. The drowsy state persisted for about 45 minutes, after which time the patients became more aware of their surroundings, though still remaining relaxed and co-operative.

The two patients in whom conditions were considered poor were tearful before treatment, but though they remained upset and difficult throughout, they had no memory of their dental experience. Dental procedures were never curtailed or abandoned despite the fact that seven of the patients had been referred by their general dental practitioners because of failure to complete treatment under local anaesthesia alone.

\section{Methods}

\section{Psychiatric Aspect}

Patients selected by the dental surgeon as unable to accept conventional dental treatment under local anaesthesia because of fear or anxiety were allocated to the study group. A control group willing to accept conventional methods of treatment was matched with the study group for sex and age. All the patients in both groups were interviewed, the proposed investigation was explained, and a full psychiatric history was taken. The intensity of anxiety concerning dental treatment was assessed and rated on a five-point scale. Patients were also requested to complete an Eysenck personality inventory, a test designed to measure neuroticism and extroversion. Eysenck and Eysenck (1964) described these as the two basic bipolar factors in personality structure. Briefly, neuroticism may be defined as emotional lability, and over-responsiveness, and liability to neurotic breakdown under stress, while extroversion implies the presence of an outgoing personality with uninhibited social tendencies.

The patients were also given three tests involving accuracy, speed, and motor co-ordination. The first consisted of inscribing two vertical lines and one horizontal line in as many $1 \mathrm{~cm}$. squares as possible in a given time, and the second of removing and placing pegs with both hands into appropriate holes in a pegboard. In the third test the patient, using one hand only, had to remove the pegs, invert them, and replace them in their holes in the pegboard. On each occasion there were three trials and the scores from each were added. Patients were tested before the administration of diazepam, one and a half hours after administration, and one week later. Twenty patients from each group who had completed dental treatment in less than one hour were also tested one hour after intravenous diazepam.

Memory was tested in three ways. Visual memory was tested by presenting the patients with a picture of a familiar object, which they were instructed to describe and memorize for recall at the end of treatment. Verbal memory was tested with a simple three-word sentence which patients were instructed to repeat and memorize. The first visual and verbal stimuli were applied 10 seconds before the administration of diazepam and repeated at five minute intervals for $\mathbf{4 0}$ minutes irrespective of duration of treatment. The order of presentation of visual and verbal stimuli was alternated. Inquiry was made whether the patient had experienced any pain during treatment, including the actual injection of local anaesthetic.

All patients were reinterviewed one week, three months, and six months after treatment.

\section{Results}

In each group there were 34 patients-13 males and 21 females. Their ages ranged from 16 to 54, the mean age for the study group being 27.6 years and for the control group 26.9 years. Four patients in the study group had epilepsy and one was also a spastic; there were no C.N.S. abnormalities in the control group. Seven patients in the study group and two in the control group had had psychiatric treatment. Five of the study group were currently receiving hypnotics or tranquillizers, and three epileptics were taking anticonvulsants. All but one of the patients in the study group had been persuaded by a relative or friend to accept dental treatment and were accompanied by an adult who also made the necessary appointment and other arrangements. By contrast, all the control group made their own arrangements.

The anxiety scores on the five-point scale of the patients in both groups are given in Table I. The eight patients in the study group who were rated as "very severely disturbed" presented a picture of an acute anxiety state.

TABLE I.- Number of Patients in Each Group Given Various Anxiety Scores

\begin{tabular}{|c|c|c|c|c|c|c|c|}
\hline \multicolumn{6}{|c|}{ Anxiety Score } & \multirow{2}{*}{$\begin{array}{l}\text { No. in } \\
\text { Study } \\
\text { Group }\end{array}$} & \multirow{2}{*}{$\begin{array}{l}\text { No. in } \\
\text { Control } \\
\text { Group }\end{array}$} \\
\hline Patients' & Cond & & & & Score & & \\
\hline $\begin{array}{l}\text { Normal function } \\
\text { Slightly disturbed } \\
\text { Moderately disturbed } \\
\text { Severely disturbed } \\
\text { Very severely disturbed }\end{array}$ & $\begin{array}{l}\because \\
\therefore \\
\therefore \\
\therefore\end{array}$ & $\begin{array}{l}\cdots \\
\because \\
\because \\
\cdots\end{array}$ & $\begin{array}{l}\ldots \\
\because \\
\because\end{array}$ & $\begin{array}{l}. \\
\therefore \\
\therefore \\
\therefore\end{array}$ & $\begin{array}{l}1 \\
2 \\
3 \\
4 \\
5\end{array}$ & $\begin{array}{r}0 \\
0 \\
10 \\
16 \\
8\end{array}$ & $\begin{array}{r}30 \\
4 \\
0 \\
0 \\
0\end{array}$ \\
\hline
\end{tabular}


The scores for both groups on the Eysenck personality inventory are given in Table II, as are the standardized values found by Eysenck and Eysenck (1964) for a normal population and a group suffering from anxiety neurosis. The study group had considerably higher scores for neuroticism and lower scores for extroversion than normal, and in fact closely resembled Eysenck's group of anxiety neurotics for both scores. In the controls the findings were reversed.

TABLE II.-Eysenck Personality Inventory

\begin{tabular}{|c|c|c|c|c|c|c|}
\hline \multirow{2}{*}{ Subjects } & & \multirow{2}{*}{$\begin{array}{c}\text { No. of } \\
\text { Patients }\end{array}$} & \multicolumn{2}{|c|}{ Extroversion } & \multicolumn{2}{|c|}{ Neuroticism } \\
\hline & & & Mean & $\begin{array}{l}\text { Standard } \\
\text { Deviation }\end{array}$ & Mean & $\begin{array}{c}\text { Standard } \\
\text { Deviation }\end{array}$ \\
\hline $\begin{array}{l}\text { Normal population* } \\
\text { Anxiety neurotics* } \\
\text { Study group } \quad \ldots \\
\text { Control group } \quad .\end{array}$ & $\begin{array}{l}\cdots \\
\cdots \\
\cdots\end{array}$ & $\begin{array}{r}2,000 \\
108 \\
34 \\
34\end{array}$ & $\begin{array}{r}12 \cdot 07 \\
9 \cdot 45 \\
10 \cdot 35 \\
14 \cdot 24\end{array}$ & $\begin{array}{l}4 \cdot 37 \\
4 \cdot 04 \\
3.92 \\
2 \cdot 87\end{array}$ & $\begin{array}{r}9 \cdot 07 \\
15 \cdot 79 \\
15 \cdot 67 \\
8 \cdot 41\end{array}$ & $\begin{array}{l}4.78 \\
5.06 \\
3.02 \\
3.50\end{array}$ \\
\hline
\end{tabular}

*From Eysenck and Eysenck (1964).

(Student's $t$-two-tailed test)

Study group v. control group for extroversion, $P<0.01$

The level of sedation varied during treatment. Three patients in the control group who had been deprived of sleep the previous night became transiently unresponsive for a period of under half a minute. All other patients became drowsy, but nevertheless were able to answer questions rationally and remained fully orientated. One patient, an alcoholic, became only slightly drowsy and his amnesia was of shorter duration than that of the other patients. There was no confusion, depression, depersonalization, or anxiety even when dental instruments or syringes were shown and correctly identified. The intensity of sedation waned after 15 to 20 minutes, and by 45 minutes all patients were only very slightly drowsy. A subjective feeling of calmness persisted up to 45 minutes. All patients had pronounced impairment of judgement concerning the time that the dental procedure lasted; the mean underestimate was 35 minutes for the study group and 25 minutes for the control group.

There was no retrograde amnesia, but all patients experienced some anterograde amnesia. Visual amnesia (mean duration 15 minutes) was shorter than verbal amnesia (mean duration 25 minutes) in all patients. There was no difference between the groups. Fifteen patients from the study group and 12 from the control group complained of feeling pain during administration of the local anaesthetic and made some movement. They all had complete amnesia concerning this by the end of treatment, however, and were still amnesic at the last interview six months later.

The results of the tests for motor co-ordination and dexterity are given in Table III. It will be seen that the

\begin{tabular}{|c|c|c|c|c|c|}
\hline TABLE III.-Motor Co- & $\begin{array}{l}\text { inaton } \\
\text { Diaze }\end{array}$ & $d$ Dex & erity & efore & $d$ after \\
\hline \multirow{2}{*}{ Test } & \multirow{2}{*}{ Group } & \multirow{2}{*}{$\begin{array}{l}\text { Before } \\
\text { Drug }\end{array}$} & \multicolumn{3}{|c|}{ After Drug } \\
\hline & & & 60 min. ${ }^{*}$ & $90 \mathrm{~min}$. & 1 week \\
\hline $\begin{array}{l}\text { 1. Motor co-ordination } \\
\text { (writing) }\end{array}$ & $\begin{array}{l}\text { Control } \\
\text { Study }\end{array}$ & $\begin{array}{l}64 \cdot 8 \\
68 \cdot 8\end{array}$ & $\begin{array}{l}50 \cdot 15 \\
54 \cdot 7\end{array}$ & $\begin{array}{l}64 \cdot 6 \\
69 \cdot 7\end{array}$ & $\begin{array}{l}66 \cdot 7 \\
75 \cdot 9\end{array}$ \\
\hline $\begin{array}{l}\text { 2. Motor co-ordination and } \\
\text { dexterity (two-handed) } \ldots\end{array}$ & $\begin{array}{l}\text { Control } \\
\text { Study }\end{array}$ & $\begin{array}{l}70 \cdot 7 \\
65 \cdot 7\end{array}$ & $\begin{array}{l}54 \cdot 7 \\
45 \cdot 7\end{array}$ & $\begin{array}{l}70 \cdot 2 \\
66 \cdot 2\end{array}$ & $\begin{array}{l}72 \cdot 7 \\
68 \cdot 7\end{array}$ \\
\hline $\begin{array}{l}\text { 3. Motor co-ordination and } \\
\text { dexterity (single-handed) }\end{array}$ & $\begin{array}{l}\text { Control } \\
\text { Study }\end{array}$ & $\begin{array}{l}78 \cdot 5 \\
84 \cdot 3\end{array}$ & $\begin{array}{l}58 \cdot 5 \\
66 \cdot 4\end{array}$ & $\begin{array}{l}81 \cdot 85 \\
83 \cdot 8\end{array}$ & $\begin{array}{l}83 \cdot 3 \\
85 \cdot 2\end{array}$ \\
\hline
\end{tabular}

*Based on 20 patients

Scores are the sum of three attempts, and refer to the number of items completed in a standard time.

response is the same in both groups of patients and of the same magnitude. There is considerable impairment in all tests in those patients tested at 60 minutes, but the 90 -minute values are indistinguishable from the values obtained before treatment.

\section{Anaesthetic Aspect}

\section{Methods}

Sixteen patients from the study group volunteered to submit to arterial and central venous cannulation to enable a detailed physiological study to be made of the response to diazepam. Continuous tracings were made of the E.E.G. and E.C.G., arterial and central venous pressures were recorded, serial measurements of cardiac output were made, and arterial and central venous blood samples were taken for $p \mathrm{H}, \mathrm{PCO}_{2}$, $\mathrm{Po}_{2}$, bicarbonate, and lactate/pyruvate ratio determinations. Full details of the methods and results of these studies have been published (Healy, Robinson, and Vickers, 1970).

In all other patients the pulse rate, respiration rate, and blood pressure were recorded, without cannulation. Patients rested for a minimum of 10 minutes in the supine position before control measurements were made. Diazepam was then given into an antecubital vein, undiluted, to a total dose of $0.2 \mathrm{mg} . / \mathrm{kg}$., at a rate of $10 \mathrm{mg} . / \mathrm{min}$. If the calculated total dose exceeded $10 \mathrm{mg}$. a one-minute pause was allowed beforc the remainder of the dose was given at the same rate.

The effectiveness of laryngeal closure was tested once in each patient by placing $10 \mathrm{ml}$. of Lipiodol on the back of the tongue with a syringe, and asking the patient to swallow. After treatment an anteroposterior chest $x$-ray film was taken to identify contrast medium in the bronchi or lungs. Further patients were similarly tested at various times after receiving the above dose of diazepam, and the results have been published elsewhere (Healy and Vickers, 1970).

In addition to the assessment made by the psychiatrist, recovery from the effects of diazepam was monitored by three further tests of C.N.S. function-body sway with the eyes shut, visual reaction time, and auditory flutter-fusion threshold. After a period of practice the control values were obtained for each test before the start of treatment. Testing was resumed after the completion of dental treatment and at 15-minute intervals thereafter until the results had returned to control values. Patients were then allowed to go home, accompanied by a responsible adult, and advised against returning to work, driving a motor vehicle, or taking alcohol until next day.

Body sway was measured in the anteroposterior plane by attaching a lightly tensed thread to the patient's collar on which was suspended a pointer moving in front of a scale (Vickers, 1965). After an initial five seconds for adjustment the maximum sway in a 15-second period with the eyes closed and feet together was recorded. The reaction time to a visual stimulus was measured by illuminating any one of three coloured lights. A random sequence had been previously prepared by throwing a die. Before each measurement the patient placed his dominant index finger on a fixed point on the table and only this finger could be used to operate one of three similarly coloured switches. An electric clock calibrated in 1/100 of a second was started when any light was switched on, and stopped when the similarly coloured switch was pressed by the patient. The test thus incorporated elements of discrimination, decision-making, and co-ordination. Six practice reactions were given on each occasion, and the mean of six subsequent reaction times was then taken.

The auditory flutter-fusion threshold was determined by using a random noise (white sound), modulated by a sine wave, and fed to a pair of earphones. This produces the sensation of a pulsating hiss, the frequency of which varies with the frequency of the modulating sine wave. The flutter-fusion threshold was taken to be the frequency at which pulsation was first detected while the frequency was being decreased and above which the sound seemed continuous. After three practice runs three determinations were made on each occasion. 


\section{Results}

The auditory flutter-fusion threshold was the most consistent of the tests of function used, with a coefficient of variation on triplicate readings of $8.9 \%$. The results on all three tests are given in Table IV. Owing to the tight schedule of

\begin{tabular}{|c|c|c|c|c|c|c|c|c|}
\hline & \multicolumn{8}{|c|}{ Time of Test-Minutes after Diazepam } \\
\hline & $\begin{array}{l}45- \\
60\end{array}$ & $\begin{array}{l}60- \\
75\end{array}$ & $\begin{array}{l}75- \\
90\end{array}$ & $\begin{array}{l}90- \\
105\end{array}$ & $\begin{array}{l}105- \\
120\end{array}$ & $\begin{array}{c}120- \\
135\end{array}$ & $\begin{array}{l}135- \\
150\end{array}$ & $\begin{array}{c}150- \\
165\end{array}$ \\
\hline $\begin{array}{l}\text { Auditory flutter-fusion } \\
\text { Reaction time } \ldots \\
\text { Body sway }\end{array}$ & $\begin{array}{r}0 \\
12 \\
11\end{array}$ & $\begin{array}{l}16 \\
38 \\
45\end{array}$ & $\begin{array}{l}36 \\
60 \\
69\end{array}$ & $\begin{array}{l}67 \\
77 \\
79\end{array}$ & $\begin{array}{r}77 \\
100 \\
100\end{array}$ & 80 & 88 & 100 \\
\hline
\end{tabular}

testing, not all patients were tested at all times. A patient who returned to a control value was included as "normal" at all subsequent times even if not tested. Conversely, a patient whose result was still abnormal was presumed to have been abnormal at all preceding times. Both reaction time and body sway results indicated a return to normal function between one and a half and two hours after diazepam, whereas at this time only $80 \%$ of the patients appeared to have recovered their control flutter-fusion threshold, and it was over two-anda-half hours before all the patients recovered on this test.

\section{Discussion}

Painless dental conservation has been available in this country for nearly half a century and widely used for the past 30 years at least. Nevertheless, there are still patients who are totally incapable of submitting themselves to ordinary dental procedures under local anaesthesia. A discussion of the factors which seem to have brought our patients to this condition would be out of place in this paper, and the findings will be reported elsewhere (Lautch, 1970). Nevertheless these patients differ characteristically from a normal population in that they are, on average, more timid, immature, and dependent. Many were in an acute anxiety state and had been avoiding treatment despite having long-continued pain. Some presented with a generalized anxiety neurosis; others had only a phobia of dentistry. Some of the latter group who volunteered for the concurrent physiological study accepted without demur arterial and venous cannulation under local anaesthesia and multiple connexions to a large amount of apparatus, and yet the sight of dental instruments induced intense anxiety.

Although the study group had Eysenck personality inventory scores which closely resemble the scores of patients with anxiety neurosis, conclusions must be drawn with considerable caution. These scores are consistent only when obtained under standard circumstances. Patients with a phobia of dentistry will almost certainly have a higher score for neuroticism when tested in a dental clinic than they would if tested in a neutral environment. Even so, unless this difference is considerable it would be reasonable to infer that less than $0.1 \%$ of the population would have scores for neuroticism comparable to those reported here. This gives an estimate for the number who need sedation for dentistry which is much lower than previous estimates (Central Health Services Council, 1967).

A period of amnesia was a constant finding, and though some patients complained of pain when the injection of local anaesthetic was being given, none of them remembered this. This pain, however, is relatively trivial, and it does not follow that dental extraction could be undertaken without local anaesthesia, relying solely on the amnesia produced by diazepam. On one occasion during the phvsiological study when such a painful stimulus was applied, detectable cardiovascular and respiratory responses occurred.

Subjectively, the shortening of time sense gave the impression that even prolonged treatment lasted only a few minutes.
There was a feeling of well-being due, no doubt, to the anxiolytic effects of diazepam accompanied by slowing of thinking. In retrospect all the patients found the experience pleasant, and some who had previously been treated under intermittent methohexitone expressed a clear preference for treatment under diazepam. Rather unexpectedly, the preservation of consciousness was thought by the patients to be the most desirable feature. Moreover, some patients who had dental. treatment under diazepam sedation were later able to tolerate further treatment with less sedation and in some cases without sedation at all.

From the operators' point of view the administration of diazepam made it possible to carry out treatment when this had previously been impossible, and enabled prolonged treatment to be carried out if necessary. At no time was the operator unduly anxious about the patient's welfare, nor, apart from the conditions of the study, would he have felt any need for the presence of medical assistance.

Full details of the physiological study have been published elsewhere (Healy et al., 1970), but the salient points from that study may be briefly stated. Cardiac output, arterial and central venous pressure, $\mathrm{pH}, \mathrm{PCO}_{2}, \mathrm{Po}_{2}$, and lactate/pyruvate ratio all remained within normal limits with only minor variations throughout the period of treatment. There was a moderate rise in pulse rate during administration of the drug. Some patients had incompetence of laryngeal closure during the first few minutes after drug administration, when this reflex was tested with a Lipiodol swallow (Healy and Vickers, 1970).

Detoxification and excretion of diazepam (de Silva, Koechlin, and Bader, 1966) is undoubtedly slower than the time taken for apparent recovery, which depends on the sensitivity of the method of testing. The usual methods of clinical evaluation of speech, gait, and behaviour indicated that the patients were safe to leave the dental hospital one hour after diazepam if accompanied by a responsible adult. Impaired performance, however, was demonstrable for longer than this in some patients. At follow-up one week later some of them reported a distinct slowing of thought processes and activity immediately after treatment, and this lasted for some hours or until the next day. For this reason patients were advised not to return to work or drive a motor vehicle, and to abstain from alcohol on the day of treatment.

Three cases of superficial venous thrombosis have occurred after injection of diazepam into the back of the hand, but none after injection into the antecubital fossa. During a preliminary trial three patients were given $0.25 \mathrm{mg} . / \mathrm{kg}$. and all became unresponsive for up to half a minute. Transient unresponsiveness was also observed with the three patients in the control group who had recently been deprived of sleep. This suggests that in subjects who are not anxious intravenous diazepam has a lesser therapeutic margin than has been recommended by the Windeyer Committee (1970). Conversely, since completing this study we have had referred one patient who could not be sedated with the doses recommended here. This small minority would be best referred to a dental hospital or specialized clinic for individual assessment and alternative therapy.

Nevertheless, the technique probably represents a real and practical advance in the management of patients with acute anxiety concerning dentistry, and should enable more such patients to be handled successfully by the general dental practitioner. It is acceptable to intensely anxious patients, and enables satisfactory dental work to proceed. Furthermore, it is not associated with any untoward physiological disturbances in the doses given in this study. In the long term it tends to have a beneficial effect on the patient's acceptance of dental treatment without producing any adverse psychiatric reactions.

Requests for reprints to P. J. Tomlin, Department of Anaesthetics, University of Birmingham. 
REFERENCES

Central Health Services Council (1967). Dental Anaesthesia. London, H.M.S.O.

de Silva, J. A. F., Koechlin, B. A., and Bader, G. (1966). Fournal of Pharmaceutical Sciences, 55, 692.

Eysenck, H. J., and Eysenck, S. B. G. (1964). Manual of the Eysenck Personality Inventory. London, University of London Press.
Healy, T. E. J., Robinson, J. S., and Vickers, M. D. (1970). British Medical fournal.

Healy, T. E. J., and Vickers, M. D. (1970). Proceedings of the Royal Society of Medicine. Awaiting publication.

Lautch, H. (1970). British fournal of Psychiatry. To be published.

Vickers, M. D. (1965). British fournal of Anaesthesia, 37, 296.

Windeyer Committee (1970) Report. London, Association of Anaesthetists of Great Britain and Ireland.

\title{
Androgen Function in "Psychogenic" and "Constitutional" Types of Impotence
}

\author{
ALAN J. COOPER, ${ }^{*}$ M.D., D.P.M. ; A. A. A. ISMAIL, $\dagger$ B.PHARM., PH.CH.(HON.), PH.D. \\ C. G. SMITH, ${ }^{*}$ M.R.C.P.I., D.P.M. ; J. A. LORAINE, $\ddagger$ D.SC., F.R.C.P.ED.
}

British Medical fournal, 1970, 3, 17-20

Cummary: Androgen function was studied in twenty-five $\checkmark$ physically healthy "primarily" impotent males classified on clinical criteria into "psychogenic" or "constitutional" groups. The mean urinary testosterone level in the former was significantly higher than in the latter group $(\mathbf{P}<\mathbf{0 . 0 0 5})$. Important variables associated significantly with higher urinary testosterone levels $(\mathbf{P}<0.05)$ were (a) "late onset" impotence, (b) shorter duration than two years, (c) stronger "sex drive," and (d) an alternative sexual outlet to orgasm and ejaculation in the three months preceding referral; the last-mentioned appeared to be the single most important discriminatory feature.

It is suggested that testosterone excretion patternsnamely, high, average, and low-may be one method of classifying impotence.

\section{Introduction}

The role of the central nervous system and the endocrine glands, especially the testes, in the aetiology of male potency disorders has been largely neglected. This has perhaps been due to two factors-namely $(a)$ the widely held view that most cases of impotence are of psychogenic origin (for example, Simpson (1950), Strauss (1950), and Stafford-Clark (1954), are among many who consider that "at least $90 \%$ of all cases of impotence are psychogenic"), and (b) the technical difficulties in assaying various hormones and their metabolites in body fluids in health and disease. Recently, however, some elegant animal experiments (Michael, 1968) as well as observations in man (Kinsey, 1953; Masters and Johnson, 1966) have redirected attention to the important functional interaction of the brain and the sex hormones in regulating libido and copulatory behaviour. In man probably some hypothalamic structures, perhaps initiated and controlled by a "sex centre" $\$$ located deep within the temporal lobes, have an important role in the production and release of "sexual" trophic hormones (notably gonadotrophins) from the anterior pituitary; in turn these may influence testicular syntheses and secretion of testosterone and other C19 steroids and ultimately sexual behaviour.

* Lecturer, Department of Psychiatry, University of Edinburgh, Edinburgh, EH10 5HF

† Member of Scientific Staff, Medical Research Council, Clinical Endocrinology Research Unit, Edinburgh, EH1 2QW.

₹ Director, Medical Research Council, Clinical Endocrinology Research Unit, Edinburgh, EH1 2QW.

SRecent observations suggest that the temporal lobes have a special significance in mediating and maintaining libido and potency. It has been postulated that the different modalities of sensory sexual input are processed in the temporal lobes which via the limbic system initiate a sexual response (Cooper, 1969a).

Reprints from Alan J. Cooper.
The technical problems of assaying $\mathrm{C} 19$ steroids such as testosterone (17 $\beta$-hydroxy-androst-4-en-3-one), the most potent naturally occurring androgen so far known, and its $17 \alpha$-epimer epitestosterone (17 $\alpha$-hydroxy-androst-4-en-3-one) have now been largely overcome; thus the possible role of these substances in the pathogenesis of impotence can be examined.

Cooper (1968, 1969b, 1969c) has inferred two main aetiological types of impotence, designated as predominantly "constitutional" and predominantly "psychogenic," which differ in development, clinical features, and prognosis. In a search for non-clinical objective criteria to support this classification a study of androgen function was undertaken in an impotent population. Additionally, to identify any possible relationship between levels of the $\mathrm{C} 19$ steroids, testosterone and epitestosterone, and important clinical variables, appropriate statistical analyses were made. This communication presents some of the findings.

\section{Patients and Methods}

Impotence was defined as the persistent inability to develop and/or maintain a penile erection sufficient to conclude coitus to orgasm and ejaculation (Hastings, 1963). A total of 25 subjects who presented in a psychiatric outpatient department with a primary complaint of impotence were studied; these were made up of (a) 20 who suffered predominant $(>50 \%$ of the time) erectional insufficiency which precluded penetration, and (b) five who, generally able to penetrate ( $>50 \%$ of the time) despite adequate intravaginal thrusting, lost their erection before orgasm and ejaculation could be attained (impotentia ejaculandi) (Johnson, 1965). At the time of presentation all were physically healthy and ambulant, there was no evidence of organic disease, and apart from some anxiety symptoms in five individuals no significant psychiatric disorder was elicited. At least one week before the endocrine investigation each patient was clinically typed (by A.J.C. or C.G.S.) as either predominantly constitutional or predominantly psychogenic according to the relative dominance of the distinguishing features summarized in Table I. At this time two psychological tests, the Eysenck Personality Inventory (E.P.I.) (Eysenck and Eysenck, 1964) and the hostility scale (Foulds, 1965), were also made; these measure respectively "neuroticism" and extroversion-introversion, and degree and direction of punitiveness. It should be emphasized, however, that the psychological test findings played no part in the classification process; this was done on purely clinical grounds. Table II sets out some important clinical data on the 25 impotent subjects of study.

Hormone Assays.-Urinary testosterone and epitestosterone 